\title{
Ulysses and I: Joyce as a catalyst for graphic practice
}

Helena Gregory, Manchester Metropolitan University

\begin{abstract}
This article will focus on elements of my graphic design practice that consider how text can inspire, be used with and act as imagery. I discuss my master's project, an investigation into a reader's response to text and a traditional graphic application of that research. This second project was made in collaboration with Joseph Haigh, a fellow student at Manchester Metropolitan University whose research is concerned with typographic landscapes. I consider how my haptic perception of the book has influenced this later work and how it continues to inspire my recent image-based responses.
\end{abstract}

\section{Keywords}

graphic design

literature

James Joyce

Ulysses

reader-response

book design

I have a long-standing interest in text and its relationship to image. This intrigue grew as I realized that fundamentally, graphic design was communication through a combination of pictures and words. My undergraduate projects examined dialogues I could create between text and image, such as the metaphors mimicry could create in a page layout. I would 
position and reshape the text in reaction to images or the ideas of an article, encouraging the audience to deepen their reading of the piece and take pleasure in looking. I focused on the relationship between a series of pictures and their title(s) and considered how their placement on the page affected the viewer's understanding. Though limited, these experiments located an area of interest to expand upon.

During my master's I inverted my approach to text and placed myself in the position of the consumer. I generated a body of research visualizing a reader's response to James Joyce's modernist novel, Ulysses. ${ }^{1}$ The project, which focused on both visual and tangible reactions to the book, was informed by theoretical pieces such as 'The reading process: A phenomenological approach' (Iser 1972) and the 'Phenomenology of reading' (Poulet 1969). Iser's work discuses of the role of the reader, arguing that a literary work is realized through the reader's engagement with the text (1972: 279). This idea is also found in Poulet's text where he considers how the divisions between book-object, text, author and reader dissolve as we read. Poulet suggests that the book ceases to be just an object in the world, instead it becomes a 'series of images, of words and of ideas' that exist in the 'innermost self' (1969: 54). These texts supported my work by suggesting that the reader is the one who transforms the book.

I contextualized my work within the broad range of pictorial responses to Joyce, a history documented in Joyce in Art: Visual Art Inspired by James Joyce (Lerm Hayes 2004). ${ }^{2}$ Modern interpretations of Joyce that influenced my practice included Drawing the Wake, an exhibition by Clinton Cahill. Cahill's work sought to illustrate a direct encounter with Joyce's experimental text, Finnegans Wake. The main body of work was a series of charcoal sketches created while reading the text (Cahill 2016). This technique became a useful tool in my own research as I attempted to capture the images provoked by 
Ulysses.

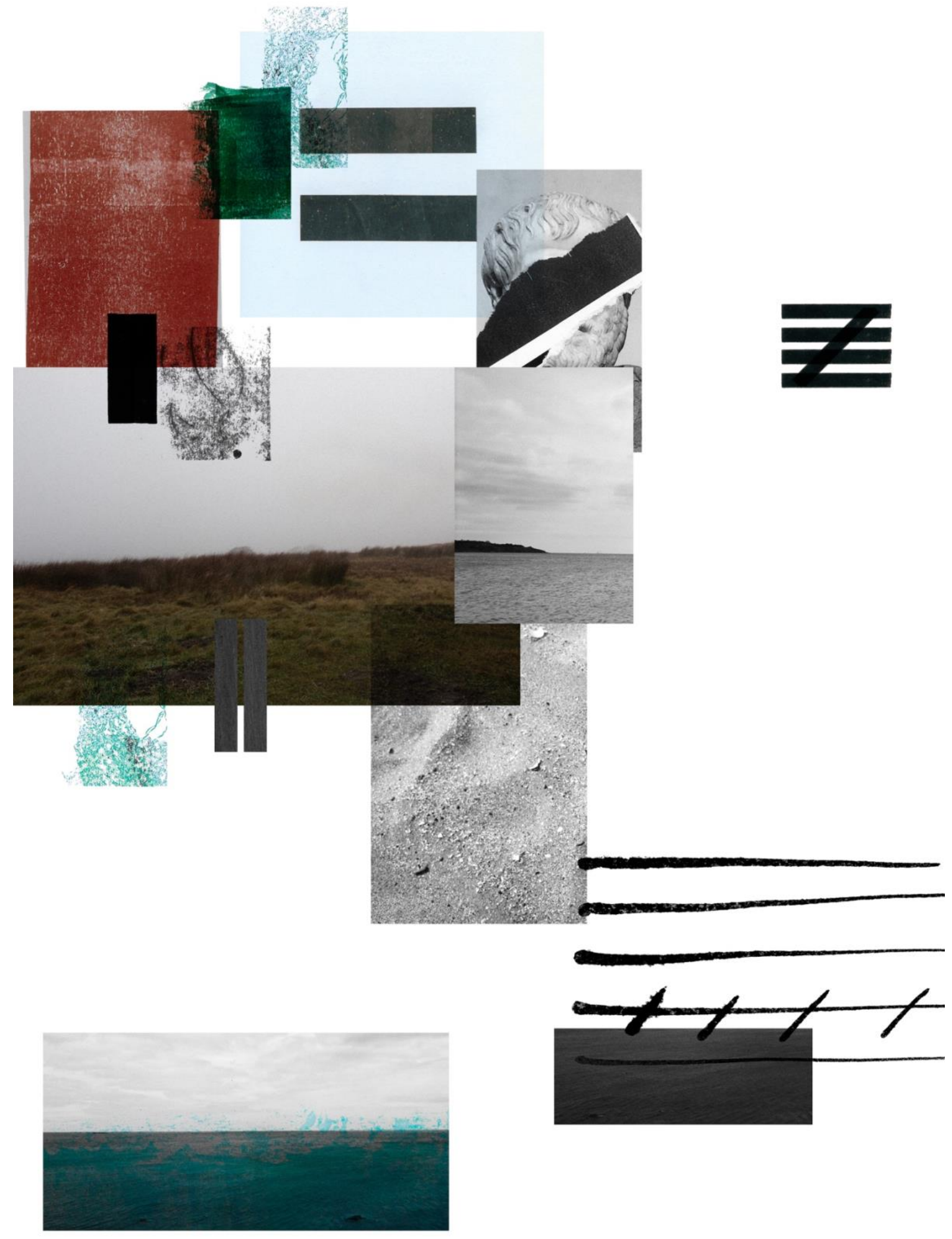


Figure 1: Proteus - Montages emulated the mental images I saw while reading Ulysses.

I created montages based on sketches and notes made as I re-read the novel (Figure 1). They attempted to imitate the mental imagery that unfolded as I read Ulysses. I had initially produced my responses as books with pages containing single images but realized that the presentation of the work was too fragmentary. Unlike the seamless imagery of the mind's eye, the viewing was interrupted. I combined the work into one composition. The flowing appearance of these montages reflected the uninterrupted movement of a mental impression. They also offered insight into the mood and appearance of my reading. I saw my difficulty in understanding the novel reflected through the inclusion of indistinct illustrative marks. The various moods of Ulysses, such as the opening part's gloominess, became evident through the tonality of my work. I had developed a method for producing visual records of my reading that could inform my design decisions in later editorial projects.

Although the montages responded to reading at an intellectual level, this textual approach neglected the curiosity I developed for the book's form. This was less a graphic designer's fixation (of paper, print and layout) and more an awareness of the book's physical presence in my hands. I photographed different copies of Ulysses to capture the book as a material object. I had chosen photography because of its representational qualities, assuming that any photographs I took would be accurate depictions of the book. However, its physicality was compressed by the photograph's flat surface. I overlaid multiple images to subvert this and create a sense of surface depth (Figure 2). I realized that in doing this though, I had returned to the conceptual act of reading. I had vizualized the transition between material reality and consciousness described by Poulet in the 'Phenomenology of reading'. The camera seemed to be drawn towards the book in my image like Poulet's reader is asked to 
'exist' in its pages. The weightlessness I had given the book by removing it from its context emphasized this idea by suggesting an existence not in 'external space', but (again) in the ‘innermost self’ (Poulet 1969).

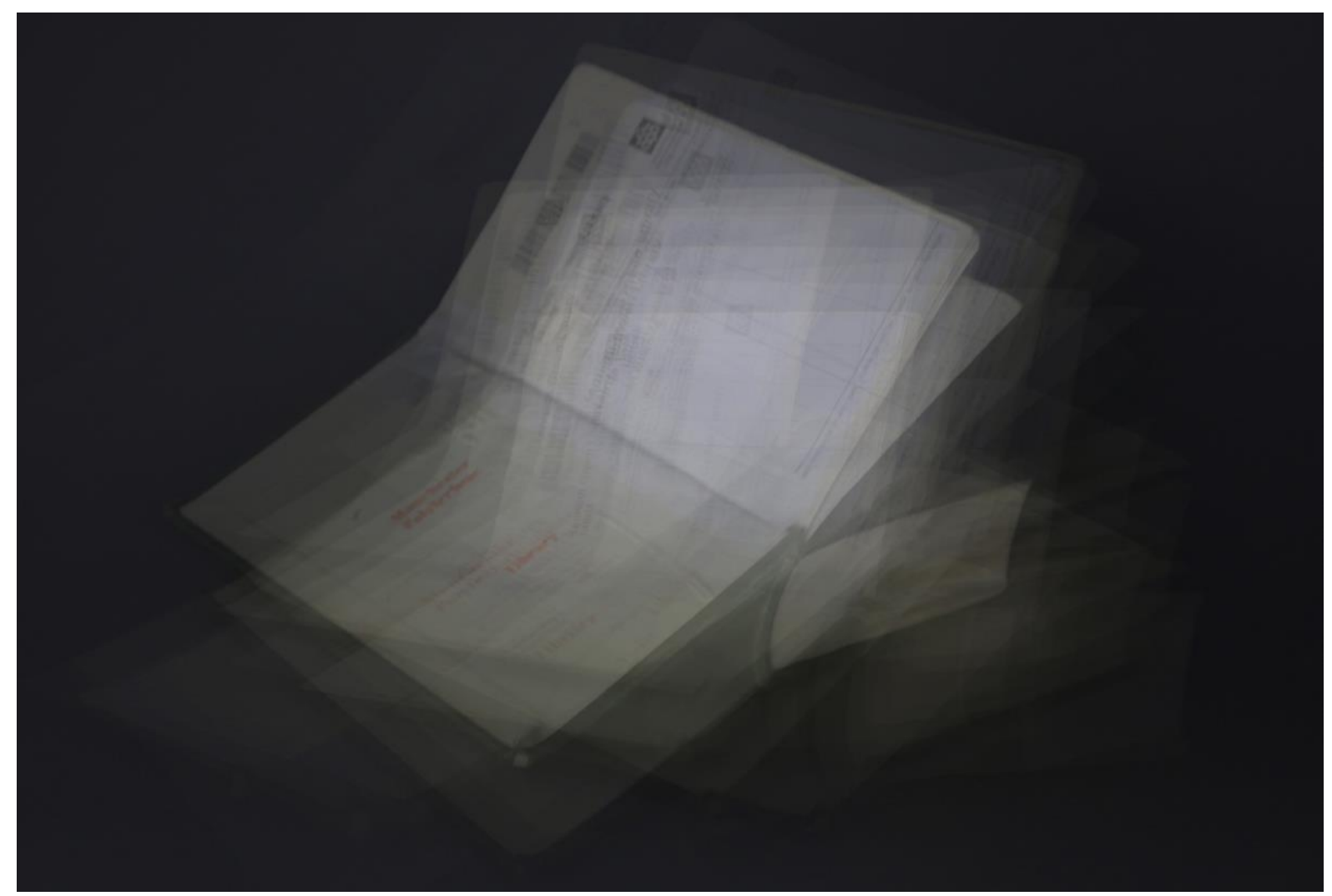

Figure 2: Book-thing - the layered photographs of the book expanded the image surface.

Interpreting reading through my work gave me a deeper understanding of the process by translating it into my language. I wondered how I could apply this research and answer the questions it raised through a piece of traditional graphic design. I asked myself, if the book fell away during reading, how appropriate would it be to play with its materiality? How could I ensure that my design fused with the narrative during the process of reading? And had the physicality of the book become more important in the digital age? I became aware that the book's materiality was longer simply at the service of the text but an attribute to be enjoyed by the reader in its own right. 
I produced a collaborative re-design of Joyce's final story from Dubliners (Joyce [1914] 1926), 'The Dead' ${ }^{3}$ to explore these ideas. The relatively short text offered great narrative depth, and as another of Joyce's works, seemed an appropriate expression of my MA research. I again visualized ideas provoked by the text and referenced them through typographic imagery in the re-working (Figure 3). Each adjustment was gradual so the design blended with the text as the book was read. We drew on my investigation into the physicality of Ulysses by focusing on our reaction to a particular copy of Dubliners. The book's distinct paper prompted us to consider how we could utilize paper stock in our version. We decided to slowly thin the paper weight out to allude to protagonist, Gabriel Conroy's increased exposure throughout the story.

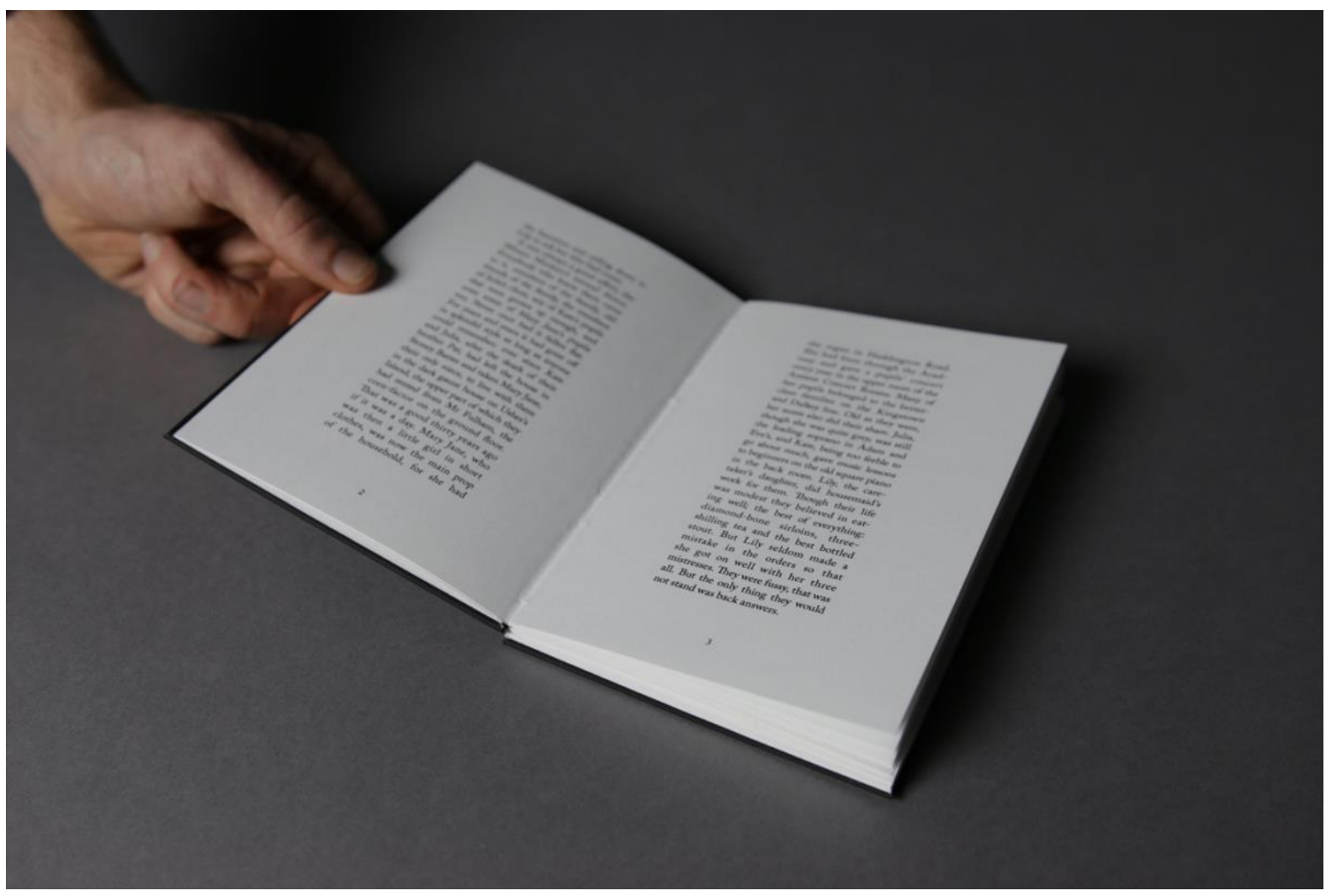

Figure 3: 'The Dead' - inside the book typographic images react to the story. We expanded and contracted the text's surface area to reflect the coming and going of guests.

'The Dead' prompted further work that drew on my interest into image and text. We 
produced screen prints that presented story over itself to create typographic imagery (Figure

4). The pieces also seemed to respond to the same tension between the visible and tangible as my photographs of Ulysses (Figure 2). By superficially layering the text, we asked the viewer to penetrate a print's various (non)surfaces as my photographs and the book asked the reader to live inside them.

This ongoing reaction to graphic surface is a natural extension of my fascination for the relationship between text and image. In my previous work, I attempted to create dialogues between elements on a page's exterior. My recent projects have subverted that surface through layering and shadows but my ambition to produce complex graphic façades that entice the reader/viewer remains.

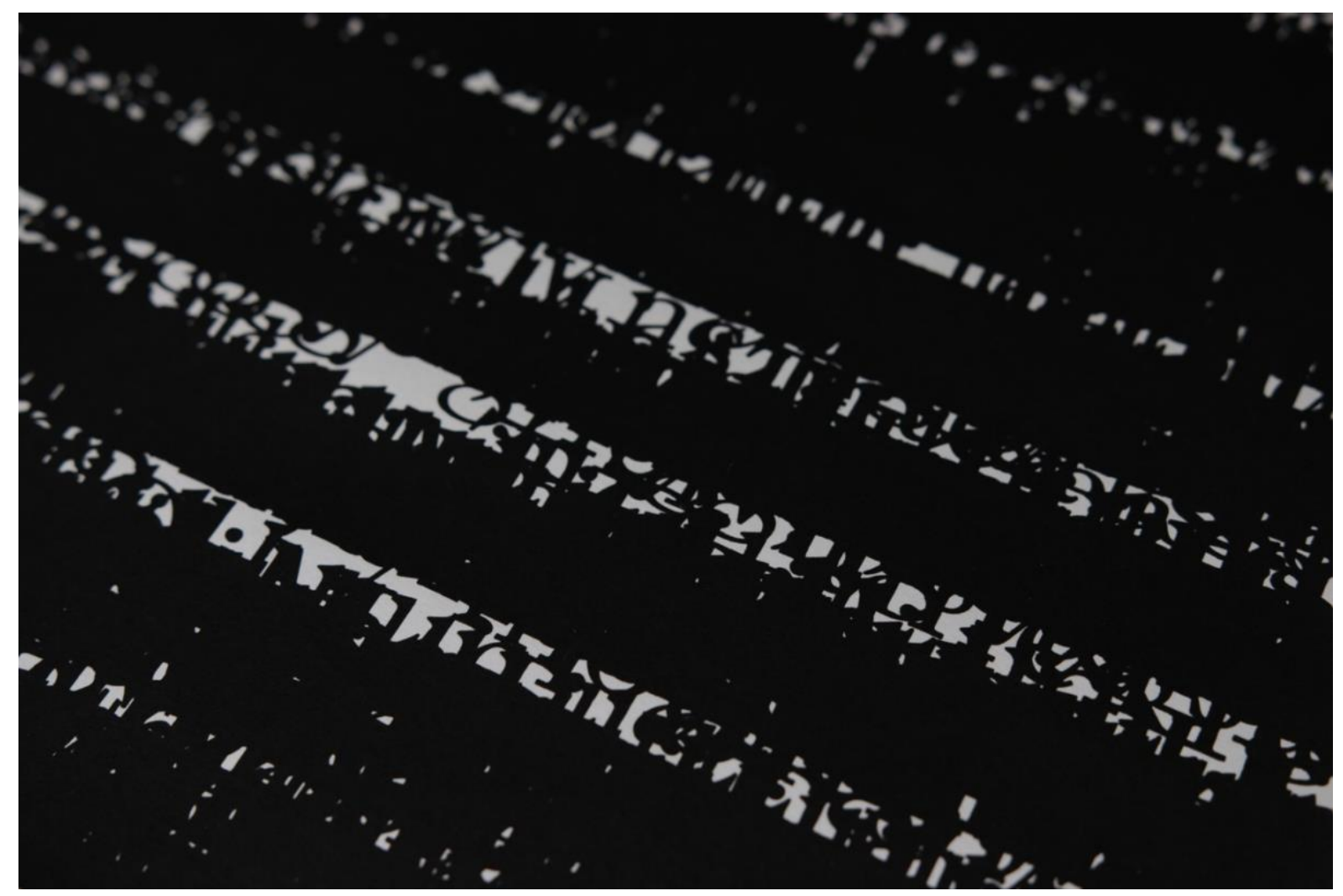

Figure 4: Screen-prints compressed the duration of reading was into a unified, impenetrable abstract form. 


\section{$\underline{\text { References }}$}

Cahill, C. (2016), Drawing the Wake, Manchester: MMU Special Collections.

Iser, W. (1972), 'The reading process: A phenomenological approach', New Literary History, 3:2, p. 295, www.jstor.org/stable/468316?seq=1\#page scan tab contents. Accessed 14 January 2018.

Joyce, J. ([1914] 1926), Dubliners, London: Jonathan Cape. ([1922] 2000), Ulysses, London: Penguin.

Lerm Hayes, C. (2003), 'Joseph Beuys 'Extends' James Joyce’s work', www.circaartmagazine.website/backissues/summer-2003-joseph-beuys-extends-jamesjoyces-work. Accessed 31 August 2017.

(2004), Joyce in Art: Visual Art Inspired by James Joyce, 1st ed., Dublin: Lilliput Press.

Poulet, G. (1969), 'Phenomenology of reading', New Literary History, 1:1, p. 54, http://www.jstor.org/stable/468372. Accessed 15 January 2018.

\section{Contributor details}


Helena Gregory is a designer and image-maker working predominantly with photography, printmaking and book design. She completed her degree in graphic design in 2016 and her MA in graphic design and art direction at Manchester Metropolitan University in 2017. Helena's research focuses on the relationship between image and text, and the perceived depth of an image's surface. She is currently working collaboratively with Joseph Haigh to explore these interests, disseminating the outcomes as Chaosmos. Joseph and Helena's recent projects include microscopic photographs of text, exhibited as part of 'Tiny' at the Sloe Gallery in Manchester and a series of images responding to the materiality of reading, produced with MMU Special Collections.

Contact:

Notes

${ }^{1}$ Ulysses recounts the fictitious events of the 16 June 1904. Through Joyce's narrative style, Leopold Bloom, the novel's central character becomes an everyman and the 16 of June transforms from simply a day to the day.

${ }^{2}$ Lerm Hayes surveys an array of projects and approaches from Richard Hamilton and his initially literal treatment of the novel to Joseph Beuys's self-reflective Ulysses Extension (Lerm Hayes, 2004: 53-56, 302-05).

3 'The Dead' focuses on Gabriel Conroy, a teacher who experiences an epiphany about love and death after attending his aunts' dinner party. Like many of the stories in Dubliners, it is subtle and uncomfortable until reaching an abrupt and profound climax (Joyce [1922] 1926). 